\title{
An estimation of the determinants of same-day visit expenditures in Belgium
}

\author{
JAN WYNEN \\ IDEA Consult, Kunstlaan 1-2, 1020 Brussels, Belgium. \\ E-mail: jan.wynen@soc.kuleuven.be.
}

\begin{abstract}
Few studies have attempted to identify predictors for spending behaviour on same-day visits. A good understanding of these predictors, however, could serve as a guide for the planning of marketing campaigns, could help in increasing the economic benefits of day trips and could be of interest from a policy perspective. Thus the main objective of this study is to investigate the effects of a wide range of socio-demographic and same-day visit related variables on the volumes and probabilities of same-day visit expenditures. Using a unique dataset on same-day visits in Belgium, the empirical results highlight that the duration of a same-day visit, age, information, education and motivation are important determinants of same-day visit expenditures.
\end{abstract}

Keywords: tourism expenditures; Tobit; heterogeneity; non-linear effects; two-step model

Tourism today not only carries socio-cultural and political significance but also provides considerable economic benefits. According to the European Tourism Satellite Accounts (TSAs), Europe is the number 1 tourist destination in the world. The tourism sector employs between about 8.6 and 24 million people in the European Community (corresponding to around 4 and $11 \%$ of total labour force) and creates $4-11 \%$ of the Community's GDP (TSA, 2010). This major economic importance of tourism for the economy has increased awareness of the importance of the sector, its socio-cultural and environmental impacts, as well as its contributions to the achievement of the goals of the Lisbon strategy - to increase economic growth, and create more and better jobs. Realizing the growing significance of tourism, governments, local authorities and private sectors in many countries, regions and communities have thus begun to funnel their resources into tourism development.

Tourism expenditure comprises three items: inbound, outbound and domestic tourism. According to the European TSAs, overnight visitors contributed most 
to expenditures on inbound and outbound tourism while, on average, same-day trips contributed more to domestic tourism expenditure than overnight trips. The share of domestic tourism expenditure in internal tourism expenditure averaged $69 \%$ for countries in the EU (TSA, 2010); the remaining 31\% was for inbound tourism. Since domestic tourism expenditures make a significant contribution to the economy in almost every European country and same-day expenditures are an important part of these domestic tourism expenditures (the Netherlands reports a $60-70 \%$ share of expenditure by same-day visitors in total domestic expenditure (TSA, 2010)), it is remarkable that so little research has been done on this topic. The existing literature has focused on tourism expenditures by overnight visitors, thus concentrating on inbound tourism. Furthermore the empirical results are not so clear-cut. Utilizing a newly created database and applying advanced econometric methods this paper adds to the existing literature by examining how a number of determinants affect expenditures for a specific form of domestic tourism, namely same-day visits.

\section{Theoretical background}

Past research has shown that tourism expenditures are contingent on a number of factors. Length of stay, travel party size and purpose of the trip are among the most cited variables to have an effect on tourism expenditures. Several studies report a positive relation between length of stay and tourism expenditures (Kozak et al, 2008; Laesser and Crouch, 2006; Leones et al, 1998; Mehmetoglu, 2007; Mok and Iverson, 2000; Pouta et al, 2006; Seiler et al, 2002). However, some studies (Roehl and Fesenmaier, 1995, Perez and Sampol, 2000; Thrane and Farstad, 2011) came up with results indicating a non-linear relationship. The above studies, however, do not agree on the direction of this relationship. Roehl and Fesenmaier (1995) conclude that length of stay has a concave relationship with tourism expenditures while Perez and Sampol (2000) and Thrane and Farstad (2011) indicate a convex relationship between tourism expenditures and length of stay.

The effects of travel party size on tourism expenditures are also ambiguous. Taylor et al (1993) and Mok and Iverson's (2000) suggest a negative relationship between tourism expenditures and size of travelling party, while Argawal and Yochum (1999) and Downward and Lumsdon (2000, 2003) come up with positive effects for travel party size on tourism expenditure. Thrane and Farstad (2011) conclude that travel party, just as length of stay, has a non-linear effect on domestic tourism expenditures. They find a convex (U-shaped) relationship between travel party size and tourism expenditures.

Furthermore several studies (Becken and Gnoth, 2004; Cai, 1998, 1999; Cai et al, 1995; Darbis et al, 1994; Lee, 2001) indicate that the purpose of the trip, but also socio-demographic characteristics of the samples studied, play an important role as predictors of tourism expenditures. Several studies (Downward and Lumsdon, 2003; Fredman, 2008; Thrane and Farstad, 2011) have found a positive effect of household income on tourism expenditures. These confirm the findings of the existing literature, which reports a positive relationship between income level and tourism expenditures (Jang et al, 2004; Lee, 2001; Wang et al, 2006). 
Studies focusing on identifying the characteristics determining tourism expenditures have tended to investigate the effect of a wide range of variables on the expenditures using simple methodologies such as comparisons of frequencies, $t$-tests, one-way analysis of variance, logistic regression and ordinary least squares (OLS). The used data, however, demand for a review of the methodologies used in the field of tourism in general. By using more advanced econometric methods, a more detailed analysis is possible. Not only the effect of a wide range of variables on the size of tourism expenditures can be analysed, but also the probability of tourism expenditures during a same-day visit can be examined.

\section{Data sources, variables and descriptive statistics}

In our analysis, a same-day visit is defined as follows:

'A same-day visit has to take place no more than $20 \mathrm{~km}$ from home (except for round trips on foot, by bike, by horse) and should take at least four hours (inclusive of travel time), without spending the night somewhere else. Sameday visits should not include: visiting family, friends and acquaintances, business trips, day trips from a holiday address or second home, or trips of a routine character (for example, frequently doing sports, daily shopping and travelling between home and work).'

Following this definition, we analyse the effect of both socio-demographic and day trip related variables by drawing on data gathered by IVOX and IDEA Consult as part of a study to examine same-day visits in Belgium. This study was commissioned by a consortium of major tourism organizations and is part of an attempt to increase the understanding of tourism expenditures in Belgium. The data are based on a survey and contain a wide range of sociodemographic and day trip related variables. The data examined here were collected on a weekly basis and cover a 6-month period (July-December 2010). The respondents were selected to be representative of the Belgian population. Each week, they were asked by e-mail whether or not they had made a sameday visit and, if so, to fill in a questionnaire. If respondents failed to answer they were replaced by someone with the same characteristics. For each week, information is available for $+/-2,000$ respondents. Information on the number of same-day visits and the corresponding expenditure is presented in Table 1.

As noted above, very few papers have attempted to identify the determinants of spending behaviour on domestic tourism, let alone on same-day visits, using advanced econometric methods. A wider range of papers, examining how a number of determinants affect tourism expenditures in general does however exist. As recommended by these prior studies, we include a broad range of variables. One such variable is the natural logarithm of family income. Family income is expected to have a positive relationship with the size of expenditure during the same-day visit (Downward and Lumsdon, 2003; Fredman, 2008; Thrane and Farstad, 2011). The analysis also controls for age and, in order to control for a possible non-linear relationship, includes the square term of this 
Table 1. Descriptive statistics: means (standard deviation).

\begin{tabular}{lccc}
\hline Month & $\begin{array}{c}\text { Number of } \\
\text { same-day visits }\end{array}$ & $\begin{array}{c}\text { Number of } \\
\text { same-day visits } \\
\text { where a non-zero } \\
\text { expenditure is } \\
\text { reported }\end{array}$ & Mean expenditures $^{* * *}$ \\
July & 393 & $132(34 \%)$ & 43.16 \\
August & 299 & $96(32 \%)$ & 51.38 \\
September & 231 & $76(33 \%)$ & 46.53 \\
October & 177 & $72(41 \%)$ & 64.03 \\
November & 122 & $59(48 \%)$ & 68.97 \\
December & 90 & $58(64 \%)$ & 51.10 \\
July-December & 1,312 & $493(38 \%)$ & \\
\hline
\end{tabular}

Notes: *Percentage of total same-day visits is presented in parentheses; * the mean is calculated based on non-zero expenditures.

variable. Furthermore, the survey identifies whether or not the day trip took place in a group and contains information on the size of the group. We also include a set of five destination dummies to control for heterogeneity across destinations. Since we are using pooled cross sections, we include season dummies to account for aggregate changes over time (Wooldridge, 2002). Following Thrane and Farstad (2011), the variable time as well as the squared form is included; these will give an indication on the duration of a same-day visit, while controlling for a possible non-linear relationship. Furthermore a long list of dummies is taken into account; these assess the impact of marital status, gender, education (divided over three dummies: master, indicating whether or not the highest obtained degree of the respondent is a Master's degree or higher; bachelor, indicating whether or not the highest obtained degree of the respondent is a Bachelor's degree; high school, indicating whether or not the highest obtained qualification of the respondent is a high school certificate; no degree (omitted variable) is used as a benchmark), profession (indicating whether or not the respondent has a job), info (indicating whether or not the respondent visited websites, read books, articles, etc, in order to prepare for the day trip), weekday (indicating if the same-day visit happened during the week or at the weekend), motivation (divided over two dummies; relaxing and family moment, learning (omitted variable) is used as a benchmark). Table 2 shows definitions, means and standard deviations for the variable used in the estimation.

\section{Empirical analysis}

To estimate the relationship between the variables outlined above and expenditures during same-day visits, a specific econometric model is required. OLS is not suitable because it does not take into account that expenditures frequently take a value of zero. Another drawback of OLS estimation is that marginal effects are constrained to be constant, which is an unrealistic assumption in our model. As a first approximation, we therefore estimate a 
Table 2. Variable definitions: means (standard deviation).

\begin{tabular}{|c|c|c|c|}
\hline Name & Description & Mean & SD \\
\hline Expenditure & Logarithm of the total expenditures during a same-day visit & 1.32 & 1.82 \\
\hline Family income & Logarithm of the family income & 7.78 & 0.43 \\
\hline Time & Variable indicating the duration of a same-day visit (hours) & 9.30 & 3.65 \\
\hline Time sq & Squared term of time & 99.89 & 84.83 \\
\hline Group activity & $\begin{array}{l}\text { Dummy variable equal to } 1 \text { if the same-day visit was an } \\
\text { organized group activity; } 0 \text { if not }\end{array}$ & 0.13 & 0.34 \\
\hline Size group & Variable identifying the size of the group & 3.79 & 4.59 \\
\hline Size group sq & Squared term of group size & 35.41 & 184.13 \\
\hline Age & Variable indicating the age of the respondent (years) & 46.93 & 13.40 \\
\hline Age sq & Square term of age & $2,397.40$ & $1,323.00$ \\
\hline Married & Dummy indicating if the respondent is married & 0.65 & 0.48 \\
\hline Gender & Dummy indicating the gender of the respondent & 0.49 & 0.50 \\
\hline Master & $\begin{array}{l}\text { Dummy variable equal to } 1 \text { if the respondent had a } \\
\text { Master's degree or higher; } 0 \text { if not }\end{array}$ & 0.16 & 0.37 \\
\hline Bachelor & $\begin{array}{l}\text { Dummy variable equal to } 1 \text { if the highest degree } \\
\text { obtained by the respondent was a Bachelor's degree; } \\
0 \text { if not }\end{array}$ & 0.20 & 0.40 \\
\hline High school & $\begin{array}{l}\text { Dummy variable equal to } 1 \text { if the highest qualification } \\
\text { obtained by the respondent was a high school certificate; } \\
0 \text { if not }\end{array}$ & 0.34 & 0.47 \\
\hline Profession & $\begin{array}{l}\text { Dummy variable equal to } 1 \text { if the respondent had a } \\
\text { profession; } 0 \text { if not }\end{array}$ & 0.68 & 0.46 \\
\hline Weekday & $\begin{array}{l}\text { Dummy variable indicating if the same-day visit } \\
\text { happened during the week }\end{array}$ & 0.39 & 0.49 \\
\hline Info & $\begin{array}{l}\text { Dummy variable equal to } 1 \text { if the respondent prepared } \\
\text { for the same-day visit by visiting websites, reading } \\
\text { books or articles, etc; } 0 \text { if not }\end{array}$ & 0.67 & 0.47 \\
\hline Family momen & $\begin{array}{l}\text { Dummy variable equal to } 1 \text { if the motivation for the } \\
\text { same-day visit was to do something with the family; } \\
0 \text { if not }\end{array}$ & 0.35 & 0.48 \\
\hline Relaxing & $\begin{array}{l}\text { Dummy variable equal to } 1 \text { if the motivation for the } \\
\text { same-day visit was to relax; } 0 \text { if not }\end{array}$ & 0.45 & 0.49 \\
\hline
\end{tabular}

Tobit model for our pooled cross sectional data, with the natural logarithm of expenditures as the dependent variable. We are using a pooling of cross sections, so there is no replicability over time. If units appear in more than one time period, their recurrence is treated as coincidental and ignored. The model to be estimated can be written as follows:

$$
\begin{aligned}
& Y_{i}^{*}=X_{i}^{\prime} \beta+\varepsilon_{i}, \\
& Y_{i}=\left\{\begin{array}{ll}
Y_{i}^{*} & \text { if } X_{i}^{\prime} \beta+\varepsilon_{i}>0 \\
0 & \text { otherwise }
\end{array},\right.
\end{aligned}
$$


where $X$ represents a matrix of regressors, $\beta$ are the parameters that have to be estimated and $\varepsilon$ is the disturbance term. We estimate a Tobit model for our pooled cross sectional data, with the logarithm of expenditures during sameday visits as the dependent variable. Expenditure data are often better modelled as lognormal, reducing heteroscedasticity and improving the model fit. A Tobit regression model for lognormal data introduces two complications: a nonzero threshold and a lognormal $y$. Log normality is introduced by specifying:

$$
y^{\prime *}=\exp \left(x^{\prime} \beta+\varepsilon\right), \quad \varepsilon \sim N\left(0, \sigma^{2}\right)
$$

where we observe that:

$$
y=\left\{\begin{array}{l}
y^{*} \text { if } \ln y^{*}>\gamma \\
0 \text { if } \ln y^{*} \leq \gamma
\end{array} .\right.
$$

We have to take the assumption of homoscedasticity $\left(\varepsilon \sim N 0, \sigma^{2}\right)$ into account. Departure from homoscedasticity will cause the estimators to be inconsistent (Wooldridge, 2002). Consequently we also estimated heteroscedastic models were we model a heteroscedasticity term. This term includes destination and season dummies. When we perform an LR-test on heteroscedasticity, we notice a rejection of the assumption of homoscedasticity. When performing a Wald test on the joint significance of the variables in the heteroscedasticity term, the assumption of homoscedasticity is again rejected $\left(\sigma^{2}(6)=21.24\right.$ with a $p$-value of 0$)$. For what follows, only the heteroscedastic models' result is presented.

In contrast to the constant marginal effects of OLS estimation, the marginal effects of the Tobit model differ for each value of $x$ because of the nonlinear conditional mean. We are interested in the marginal effect on the probability that an observation is uncensored (5) and the marginal effect on positive outcomes (6).

$$
\frac{\partial \operatorname{Pr}(y>0 \mid x)}{\partial x_{k}}=\phi\left(\frac{x \beta}{\sigma}\right) \frac{\beta_{k}}{\sigma}
$$

where $\Phi$ stands for the standard normal cumulative distribution function.

$$
\frac{\partial E(y \mid x, y>0)}{\partial x_{k}}=\beta_{k}+\beta_{k} \frac{\partial \lambda(c)}{\partial c}=\beta_{k}\{1-\lambda(c)[c+\lambda(c)]\}
$$

As common in the literature, marginal effects are reported at the mean for the continuous regressors, and for a jump from 0 to 1 for dummy variables on the right-hand side. Standard errors for the marginal effects are obtained by the delta method (Greene, 2000). A Tobit estimation is a popular approach in empirical studies on spending behaviour. However next to a one-step approach, such as the Tobit estimation, there is also a two-step approach. From an 
econometric point of view, a two-step approach is well worth considering because the Tobit model is very restrictive. In the Tobit model any variable that increases the probability of a non-zero value must also increase the mean of the positive values; a positive element of $\beta$ means that an increase in the corresponding variable (element of $\left.X_{t}\right)$ increases both $\mathrm{P}\left(y_{y}>0\right)$ and $\mathrm{E}\left(y_{t} \mid y_{t}>\right.$ $0)$. In order to find the best model specification two alternative models are tested against each other, following Cragg (1971). The first specification estimates a single censored Tobit model. The Tobit model uses all the available information from the explanatory variables; it includes, however, both the decision whether or not to spend money, and the level of the expenditure, in one model. The alternative specification separates the decision of whether or not to make an expenditure from the decision of how much to spend. The first stage uses the whole data set and considers the decision whether or not to spend money using a probit model. ${ }^{1}$ For the second stage only the subset of variables thatdo spend money are considered. A truncated estimation procedure ${ }^{2}$ is used as the dependent variable is observed only if it is greater than zero. The two parts are assumed to be independent and are estimated separately. The two part model is given below in Equations (7) and (8). ${ }^{3}$

$$
\begin{aligned}
& Y=\alpha+\beta_{1} \text { Infamilyincome }+\beta_{2} \text { time }+\beta_{3} \text { time }{ }^{2}+\beta_{4 \text { groupactivity }+} \\
& \beta_{5} \text { Sizegroup }+\beta_{6} \text { Sizegroup }{ }^{2}+\beta_{7} \text { Age }+\beta_{8} \text { Age } e^{2}+\beta_{9} \text { Married }+\beta_{10} \text { Gender }+ \\
& \beta_{11} \text { Master }+\beta_{12} \text { Bachelor }+\beta_{13} \text { Highschool }+\beta_{14} \text { Profession }+\beta_{15} \text { Weekday }+ \\
& \beta_{16} \text { Info }+\beta_{17} \text { Info }+\beta_{18} \text { Familymoment }+\beta_{19} \text { Relaxing }+\varepsilon .
\end{aligned}
$$

Where $Y=1$ if $x>0, x$ is exports and $Y=0$ if $x=0$. For the firms for which $Y=1$ :

$$
\begin{aligned}
& \text { PX }=\delta+\gamma_{1} \text { Infamilyincome }+\gamma_{2} \text { time }+\gamma_{3} \text { time }^{2}+\gamma_{4} \text { groupactivity }+ \\
& \gamma_{5} \text { Sizegroup }+\gamma_{6} \text { Sizegroup }{ }^{2}+\gamma_{7} \text { Age }+\gamma_{8} \text { Age } e^{2}+\gamma_{9} \text { Married }+\gamma_{10} \text { Gender }+ \\
& \gamma_{11} \text { Master }+\gamma_{12} \text { Bachelor }+\gamma_{13} \text { Highschool }+\gamma_{14} \text { Profession }+\gamma_{15} \text { Weekday }+ \\
& \gamma_{16} \text { Info }+\gamma_{17} \text { Info }+\gamma_{18} \text { Familymoment }+\gamma_{19} \text { Relaxing }+\mu .
\end{aligned}
$$

In the first part of the double specification (probit estimation) we again model a heteroscedasticity term. The heteroscedasticity term includes season and destination dummies. When performing a Wald test on the joint significance of the variables in the heteroscedasticity term the findings are confirmed (test statistic of 13.38 with corresponding $p$-value $=0$ ). In the second part of the double specification we include robust standard errors in order to deal with the heteroscedasticity. ${ }^{4}$ This double specification can be tested as the unrestricted model against a Tobit model as the restricted model. Using a likelihood ratio test the restricted model (Tobit estimation) was rejected (test statistic of $-1,499.23$ with a corresponding $p$-value of 0 ).

From an econometric point of view, the two-part model is flexible and the most attractive because it allows different covariates to have a different impact on the two parts of the model. However, in this case, an independent two-step approach can be criticized on theoretical grounds. There is no such thing as 
a two-step decision - to make an expenditure or not, and then how much to spend. The respondent chooses the most efficient, for him or her (in terms of needs), volume of expenditures, and this might be zero. So a respondent simultaneously decides if and how much to spend during a same-day visit. However, we were unable to set up a dependent two-step model (Heckman selection model) with the data at hand. ${ }^{5}$ Taking these considerations into account, the focus here is on the heteroscedastic Tobit estimation.

\section{Results}

Table 3 includes the results of the heteroscedastic Tobit estimation and the twostep model. Models 1 and 2 show the results of the two-step model, where Model 1 is the truncated regression and Model 2 is the heteroscedastic probit model. Models 3 and 4 include the results of the heteroscedastic Tobit model. Model 3 estimates the probability, while Model 4 analyses the size of the expenditure. As discussed above, the two-part model attains some of its flexibility and computational simplicity by assuming that the two parts - the decision to spend and the amount spent - are independent. Furthermore, the results of the two-step model are very similar to those of the Tobit estimation. Because of these reasons, only the results of the Tobit estimation (models 3 and 4) will be discussed.

We notice that duration of a same-day visit (time) plays both a roll on the probability to spend money and on the size of the expenditure. The square term indicates a concave (inverted $U$ ) relationship. The probability and the amount increase in the beginning of the day trip, but after 13 hours the probability to spend declines, while the amount to spend starts to decline after 12 hours. This is in line with the findings of Roehl and Fesenmaier (1995) and Thrane and Farstad (2011). Surprisingly, if the same-day visit is organized as a group activity both the possibility and the size of the expenditure decline. However, when taking the size of the group into account, regardless of being an organized group activity or not, the probability to spend money and the propensity to spend more increases with group size. However, when taking the squared term into account, the findings indicate an inverted $U$ relationship between tourism expenditure and travel party size (Figure 1).

The probability of spending money increases if the group has fewer than 17 group members, while the propensity to spend more increases if the group is smaller than or equal to 14 people. If the group includes more people, we notice a decline in both the probability of spending and the size of expenditures. Thrane and Farstad (2011) report a U-shaped relationship for the effect of travel party size on domestic expenditures. A possible explanation for this difference may be the inclusion of overnight visitors by Thrane and Farstad (2011). The variable age has a convex (U-shaped) relationship with expenditure, younger people have a higher probability to spend money and spend more than older ones. However, this is true only up to a certain point. Starting from the age of 45 , people tend to increase their spending again, while if they are over 50 the probability to spend money on a daytrip also increases (Figure 2).

Education proves to have a negative impact on expenditures during sameday visits. People with a Bachelor's degree as their highest degree spend $0.42 \%$ 
Table 3. Marginal effects of heteroscedastic probit estimation, truncated regression and hetereoscedastic Tobit.

\begin{tabular}{|c|c|c|c|c|}
\hline & $\begin{array}{l}\text { Model } 1 \\
\text { Coeff } \mathrm{n} \\
\text { (robust } \\
\text { standard } \\
\text { error) }\end{array}$ & $\begin{array}{c}\text { Model } 2 \\
\frac{\delta P\left(y_{1}=1 \mid X_{i}^{\prime}\right)}{\delta x_{i k}} \\
(\text { Std err })\end{array}$ & $\begin{array}{c}\text { Model } 3 \\
\frac{\delta \operatorname{Pr}(y>0 \mid x)}{\delta x_{k}} \\
(\text { Std err })\end{array}$ & $\begin{array}{c}\text { Model } 4 \\
\delta E(y \mid x, y>0) \\
\delta x_{k} \\
(\text { Std err })\end{array}$ \\
\hline Lnfamilyincome & $\begin{array}{c}0.15 \\
(0.50)\end{array}$ & $\begin{array}{l}0.31^{* *} \\
(2.47)\end{array}$ & $\begin{array}{c}0.03 \\
(0.80)\end{array}$ & $\begin{array}{c}0.11 \\
(0.80)\end{array}$ \\
\hline Time & $\begin{array}{l}0.37^{* *} \\
(2.29)\end{array}$ & $\begin{array}{l}0.14^{* * *} \\
(2.73)\end{array}$ & $\begin{array}{l}0.05^{* * *} \\
(3.09)\end{array}$ & $\begin{array}{c}0.18^{* * *} \\
(3.10)\end{array}$ \\
\hline Timesq & $\begin{array}{c}-0.0170^{* *} \\
(-2.20)\end{array}$ & $\begin{array}{c}-0.0041^{*} \\
(-1.92)\end{array}$ & $\begin{array}{c}-0.0019^{* * *} \\
(-3.00)\end{array}$ & $\begin{array}{c}-0.0076^{* * *} \\
(-3.00)\end{array}$ \\
\hline Groupactivity & $\begin{array}{c}-1.57^{* * *} \\
(-2.62)\end{array}$ & $\begin{array}{l}-0.25 \\
(-1.51)\end{array}$ & $\begin{array}{c}-0.14^{* * *} \\
(-3.96)\end{array}$ & $\begin{array}{c}-0.52^{* * *} \\
(-4.31)\end{array}$ \\
\hline Sizegroup & $\begin{array}{l}0.174^{*} \\
(1.90)\end{array}$ & $\begin{array}{c}-0.111^{* * *} \\
(-2.71)\end{array}$ & $\begin{array}{l}0.02^{* *} \\
(2.16)\end{array}$ & $\begin{array}{l}0.07^{* *} \\
(2.17)\end{array}$ \\
\hline Sizegroupsq & $\begin{array}{c}-0.0067^{*} \\
(-1.87)\end{array}$ & $\begin{array}{c}0.0046^{* * *} \\
(2.86)\end{array}$ & $\begin{array}{c}-0.0006^{* *} \\
(-2.28)\end{array}$ & $\begin{array}{c}-0.0025^{* *} \\
(-2.28)\end{array}$ \\
\hline Age & $\begin{array}{l}-0.18^{* *} \\
(-2.34)\end{array}$ & $\begin{array}{l}-0.05^{* *} \\
(-2.04)\end{array}$ & $\begin{array}{c}-0.02^{* * *} \\
(-3.49)\end{array}$ & $\begin{array}{c}-0.09^{* * *} \\
(-3.49)\end{array}$ \\
\hline Agesq & $\begin{array}{c}0.0020^{* *} \\
(2.38)\end{array}$ & $\begin{array}{c}0.0006^{* *} \\
(2.29)\end{array}$ & $\begin{array}{c}0.0002^{* * * *} \\
(3.61)\end{array}$ & $\begin{array}{c}0.0010^{* * * *} \\
(3.61)\end{array}$ \\
\hline Married & $\begin{array}{c}0.12 \\
(0.46)\end{array}$ & $\begin{array}{l}-0.03 \\
(-0.26)\end{array}$ & $\begin{array}{c}0.03 \\
(0.98)\end{array}$ & $\begin{array}{c}0.12 \\
(0.99)\end{array}$ \\
\hline Gender & $\begin{array}{c}-0.3 \\
(-1.22)\end{array}$ & $\begin{array}{c}-0.04 \\
(-0.44)\end{array}$ & $\begin{array}{l}-0.01 \\
(-0.58)\end{array}$ & $\begin{array}{l}-0.06 \\
(-0.58)\end{array}$ \\
\hline Master & $\begin{array}{l}-0.81 \\
(-1.41)\end{array}$ & $\begin{array}{l}-0.19 \\
(-1.31)\end{array}$ & $\begin{array}{l}-0.08^{* *} \\
(-2.01)\end{array}$ & $\begin{array}{l}-0.32^{* *} \\
(-2.11)\end{array}$ \\
\hline Bachelor & $\begin{array}{l}-0.82 \\
(-1.61)\end{array}$ & $\begin{array}{l}-0.21 \\
(-1.53)\end{array}$ & $\begin{array}{c}-0.11^{* * *} \\
(-2.87)\end{array}$ & $\begin{array}{c}-0.42^{* * *} \\
(-3.02)\end{array}$ \\
\hline Highschool & $\begin{array}{l}-0.44 \\
(-1.09)\end{array}$ & $\begin{array}{c}-0.34^{* * *} \\
(-2.84)\end{array}$ & $\begin{array}{l}-0.08^{* *} \\
(-2.25)\end{array}$ & $\begin{array}{l}-0.31^{* *} \\
(-2.29)\end{array}$ \\
\hline Profession & $\begin{array}{c}0.34 \\
(1.23)\end{array}$ & $\begin{array}{l}0.22^{*} \\
(1.88)\end{array}$ & $\begin{array}{c}0.05 \\
(1.47)\end{array}$ & $\begin{array}{c}0.18 \\
(1.50)\end{array}$ \\
\hline Weekday & $\begin{array}{l}-0.24 \\
(-0.96)\end{array}$ & $\begin{array}{l}0.18^{* *} \\
(2.05)\end{array}$ & $\begin{array}{l}-0.01 \\
(-0.24)\end{array}$ & $\begin{array}{l}-0.02 \\
(-0.24)\end{array}$ \\
\hline Info & $\begin{array}{l}0.97^{* * *} \\
(3.05)\end{array}$ & $\begin{array}{l}-0.03 \\
(-0.35)\end{array}$ & $\begin{array}{l}0.10^{* * * *} \\
(3.87)\end{array}$ & $\begin{array}{l}0.39^{* * *} \\
(3.96)\end{array}$ \\
\hline Familymoment & $\begin{array}{c}0.28 \\
(0.85)\end{array}$ & $\begin{array}{c}0.19 \\
(1.38)\end{array}$ & $\begin{array}{c}0.0328 \\
(0.88)\end{array}$ & $\begin{array}{l}0.131 \\
(0.87)\end{array}$ \\
\hline Relaxing & $\begin{array}{c}0.62^{*} \\
(1.91)\end{array}$ & $\begin{array}{l}0.29^{* *} \\
(2.46)\end{array}$ & $\begin{array}{l}0.09^{* * * *} \\
(2.68)\end{array}$ & $\begin{array}{l}0.36^{* * *} \\
(2.65)\end{array}$ \\
\hline Destination dummies & Included & Included & Included & Included \\
\hline Season dummies & Included & Included & Included & Included \\
\hline $\begin{array}{l}\text { Test on joint } \\
\text { significance of } \\
\text { destination dummies }\end{array}$ & & $\begin{array}{c}\chi^{2}(4)= \\
16.44^{* * * *}\end{array}$ & $\begin{array}{l}\chi^{2}(4)= \\
16.85^{*}\end{array}$ & $\begin{array}{l}\chi^{2}(4)= \\
16.85^{*}\end{array}$ \\
\hline Observations & 493 & 1312 & 1312 & 1312 \\
\hline $\begin{array}{l}\text { Log Likelihood } \\
\text { Test on } \\
\text { heteroscedasticity }\end{array}$ & -686.32 & $\begin{array}{l}-796.61 \\
\chi^{2}(6)= \\
45.74^{* * *}\end{array}$ & $\begin{array}{c}-1817.21 \\
\chi^{2}(6)= \\
23.05^{* * *}\end{array}$ & $\begin{array}{c}-1817.21 \\
\chi^{2}(6)= \\
23.05^{* * *}\end{array}$ \\
\hline
\end{tabular}




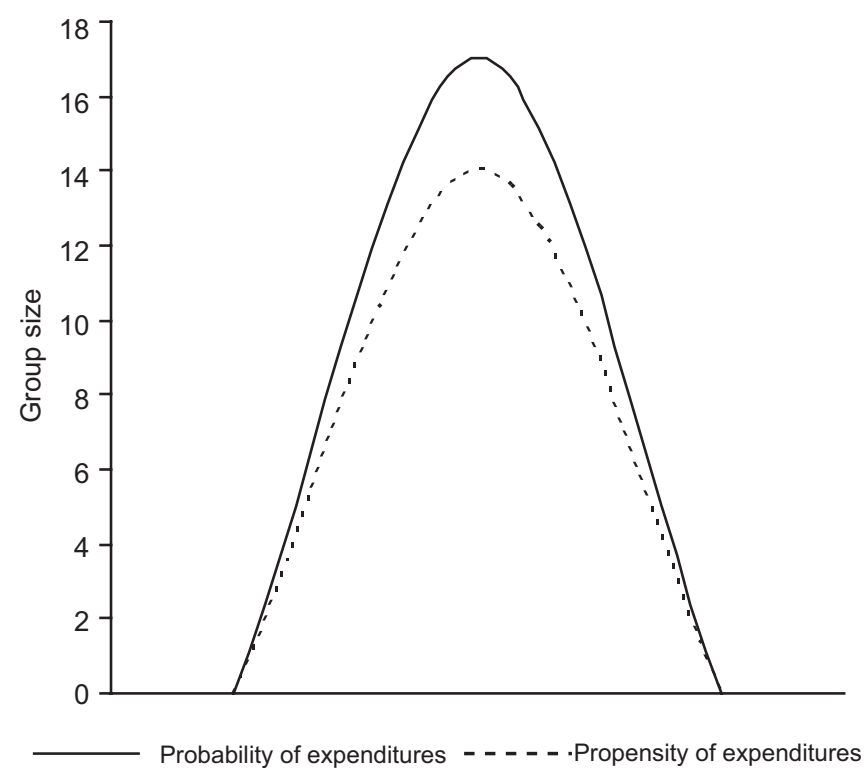

Figure 1. Effect of group size on the probability and propensity of expenditures.

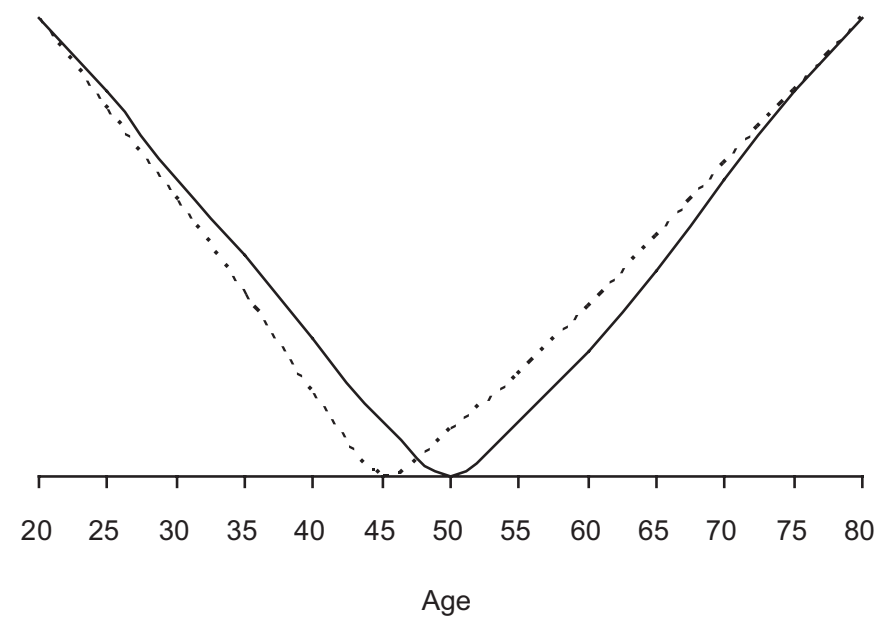

_ Probability of expenditures - - - - Propensity of expenditures

Figure 2. Effect of age on the probability and propensity of expenditures.

less than people without a degree. For people with a Master's degree or higher, this figure is $0.32 \%$. Furthermore we notice that the variable 'info' is highly significant: people who have prepared for the day trip by consulting websites, 
articles or books will not only spend more but also have a higher probability to spend money during a same-day visit. Finally not all motivation variables are significant; relaxing, however, proves to be positive and highly significant. If people go on a day trip purely to relax, the probability for expenditure increases with $0.09 \%$ and the amount spend is $0.36 \%$ higher.

\section{Discussion and conclusion}

As mentioned above in the introduction to this paper, most studies examining tourism expenditures focus on inbound tourism. However, domestic tourism and same-day visits in particular generally attract more visitors than inbound tourism. Consequently, this study's main objective was to understand the determinants of same-day visit expenditures. The methodology used was a Tobit and two-step model, taking into consideration zero expenditure categories. By following this methodology not only could the size of expenditures be analysed but the probabilities were also examined.

Certain variables seemed to be more important than others, and variations were apparent in the effects of the determinants on estimates of expenditures. Remarkably, for the variables discussed, many non-linear relationships were discovered, leading to interesting results. While some of these results, such as the duration of a same-day visit, information, age and motivation, were intuitive, others were quite surprising - specifically, the effect of group size and education. The larger the group, the higher was the propensity and probability to spend money. This proved to be true up to a certain point, after which the opposite occurred. The larger the group, the smaller were the propensity and probability to consume. A final surprising result was discovered for the education variable. People with no educational qualification had a higher probability and propensity to spend money than people with an educational qualification.

In a further study, it would be interesting to use the available dataset to research the impact of socio-demographic and day trip related variables on the choice of location of a same-day visit. This could be done by using multinomial probit or logit models. For future studies, however, it would be desirable to collect panel data over years to investigate more accurately the effect of the discussed determinants.

\section{Notes}

1. The probit model correctly predicts $66.31 \%$ of the outcomes for model 1 .

2. The error terms in the truncated regression model have a truncated normal distribution, which is a normal distribution that has been scaled upward so that the distribution integrates to one over the restricted range.

3. In both equations, season and destination dummies are included.

4. However, unlike the Tobit model, normality and heteroscedasticity are not necessary for consistency of the estimator. Conversely, it is known that the OLS estimate of the residual variance will be biased in the presence of heteroscedasticity so robust standard errors are included.

5. Since the relationship between the inverse Mills ratio (Heckman's lambda) and the estimated $\beta$ s after the probit model is strongly linear, a Heckman selection model with the same variables in the selection and structural equation was also not feasible. 


\section{References}

Agarwal, V.B., and Yochum, G.R. (1999), 'Tourist spending and race of visitors', Journal of Travel Research, Vol 38, No 2, pp 173-176.

Becken, S., and Gnoth, J. (2004), 'Tourist consumption systems among overseas visitors: reporting on American, German and Australian visitors to New Zealand', Tourism Management, Vol 25, No 3, pp 473-479.

Cai, L.A. (1998), 'Analysing household food expenditure patterns on trips and vacations: a Tobit model', Journal of Hospitality and Tourism Research, Vol 22, No 4, 338-358.

Cai, L.A. (1999), 'Relationship of household characteristics and lodging expenditure on leisure trips', Journal of Hospitality and Leisure Marketing, Vol 6, No 2, pp 5-18.

Cai, L.A., Hong, G., and Morrison, A.M. (1995), 'Household expenditure patterns for tourism products and services', Journal of Travel and Tourism Marketing, Vol 4, No 4, pp 15-40.

Cragg, J.G. (1971), 'Some statistical models for limited dependent variables with application to the demand for durable goods', Econometrica, Vol 39, No 5, pp 829-844.

Darbis, R., Soberon-Ferrer, H., and Patro, D. (1994), 'Analysis of leisure expenditures in the United States', Journal of Leisure Research, Vol 26, No 4, pp 309-321.

Downward, P., and Lumsdon, L. (2000), 'The demand for day-visits: an analysis of visitor spending', Tourism Economics, Vol 6, No 3, pp 251-262.

Downward, P., and Lumsdon, L. (2003), 'Beyond the demand for day-visits: an analysis of visitor spending', Tourism Economics, Vol 9, No 1, pp 67-77.

Fredman, P. (2008), 'Determinants of visitor expenditures in mountain tourism', Tourism Economics, Vol 14, No 2, pp 297-311.

Greene, W. (2000), Econometric Analysis, 4th edn, Prentice Hall, Englewood Cliffs, NJ.

Jang, S.C.S., Bai, B., Hong, G.S., and O'Leary, J.T. (2004), 'Understanding travel expenditure patterns: a study of Japanese pleasure travelers to the United States by income level', Tourism Management, Vol 25, No 3, pp 331-341.

Kozak, M., Gokovali, U., and Bahar, O. (2008), 'Estimating the determinants of tourist spending: a comparison of four models', Tourism Analysis, Vol 13, No 2, pp 143-156.

Laesser, C., and Crouch, G.I. (2006), 'Segmenting markets by travel expenditure patterns: the case of international visitors to Australia', Journal of Travel Research, Vol 44, No 4, pp 397-406.

Lee, H.C. (2001), 'Determinants of recreational boater expenditures on trips', Tourism Management, Vol 22, No 6, pp 659-667.

Leones, J., Colby, B., and Crandall, K. (1998), 'Tracking expenditures of the elusive nature tourists of Southeastern Arizona', Journal of Travel Research, Vol 36, No 3, 56-64.

Mehmetoglu, M. (2007), 'Nature-based tourists: the relationship between their trip expenditures and activities', Journal of Sustainable Tourism, Vol 15, No 2, pp 200-216.

Mok, C., and Iverson, T.J. (2000), 'Expenditure-based segmentation: Taiwanese tourists to Guam', Tourism Management, Vol 21, No 3, pp 299-305.

Perez, E.A., and Sampol, C.J. (2000), 'Tourist expenditure for mass tourism markets', Annals of Tourism Research, Vol 27, No 3, pp 624-637.

Pouta, E., Neuvonen, M., and Sievänen, T. (2006), 'Determinants of nature trip expenditures in Southern Finland - implications for nature tourism development', Scandinavian Journal of Hospitality \& Tourism, Vol 6, No 2, pp 118-135.

Roehl, W.S., and Fesenmaier, D. R. (1995), 'Modelling the influence of information obtained at state welcome centers on visitor expenditures', Journal of Travel and Tourism Marketing, Vol 4, No 3, pp 19-28.

Seiler, V., Hsieh, S., Seiler, M., and Hsieh, C. (2002), 'Modelling travel expenditures for Taiwanese tourism', Journal of Travel and Tourism Marketing, Vol 13, No 4, pp 47-61.

Taylor, D.T., Fletcher, R.R, and Clabaugh, T. (1993), 'A comparison of characteristics, regional expenditures, and economic impact of visitors to historical sites with other recreational visitors', Journal of Travel Research, Vol 32, No 1, pp 30-35.

Thrane, C., and Farstad, E. (2011), 'Domestic tourism expenditures: the non-linear effects of length of stay and travel party size', Tourism Management, Vol 32, pp 46-52.

Tourism Satellite Accounts (TSA) in Europe. (2010), Eurostat.

Wang, Y., Rompf, P., Severt, D., and Peerapatdit, N. (2006), 'Examining and identifying the determinants of travel expenditure patterns', International Journal of Tourism Research, Vol 8, No 5, pp 333-347.

Wooldridge, J.M. (2002), Econometric Analysis of Cross Section and Panel Data, MIT Press, Cambridge, MA. 